Research Article

\title{
Comparative Study on Torsional Shear and Triaxial Test of Asphalt Mixtures
}

\author{
Jun Xie $\mathbb{D i D}^{1,2}$ and Yifan Wang $\mathbb{D}^{1}$ \\ ${ }^{1}$ Key Laboratory of Highway Engineering of Ministry of Education, Changsha University of Science \& Technology, \\ Changsha 410114, China \\ ${ }^{2}$ National Center for Asphalt Technology at Auburn University, Auburn, AL 36830, USA \\ Correspondence should be addressed to Jun Xie; howardxj@csust.edu.cn
}

Received 24 March 2019; Revised 21 May 2019; Accepted 27 May 2019; Published 9 June 2019

Academic Editor: Xu Yang

Copyright (C) 2019 Jun Xie and Yifan Wang. This is an open access article distributed under the Creative Commons Attribution License, which permits unrestricted use, distribution, and reproduction in any medium, provided the original work is properly cited.

In order to verify the reliability and effectiveness of the torsional shear test method, a comparative study of the torsional test under normal stress conditions and triaxial test was carried out with two different asphalt types (unmodified asphalt and SBS-modified asphalt) for asphalt mixtures of AC- 13 and AC-20 at three temperatures of $20^{\circ} \mathrm{C}, 40^{\circ} \mathrm{C}$, and $60^{\circ} \mathrm{C}$. The results showed that the crack spreading routine and the spreading angle were different between the two test methods. The cohesion of the torsional test was slightly larger than that of the triaxial test for different mixtures, asphalts, and temperatures. The main cause of this result is the difference of loading mode. The internal friction angle was basically equivalent in the two methods for different mixtures, asphalts, and temperatures, which indicated that the internal friction angle was mainly related to the spatial distribution of the aggregates or the mutual interlock and had little to do with the test method and external conditions. The results of the ANOVA and regression analysis indicated that the two test methods have a good correlation, and the torsional shear test is a reliable and effective laboratory test method for evaluating the shear performance of asphalt mixtures.

\section{Introduction}

Asphalt pavement has been widely used in China's expressways and trunk highways due to its good performance. However, with the increasing traffic volume and the continuous development of heavy-duty transportation, damages such as rutting and pavement surface cracking have occurred, seriously affecting the pavement performance, driving safety, and service life of asphalt pavement.

Studies have shown that the above damages are related to the insufficient shear performance of the asphalt mixture. Especially under the triaxial nonuniform contact stress of the tire-pavement surface, there is a more concentrated shear stress distribution near the pavement surface $[1,2]$, which is related to the pavement surface damage, such as rutting and surface cracking. Myers et al. [3] found that there was a high lateral horizontal stress under the nonuniform stress, which increased the possibility of road surface cracking and rutting damage. Wang et al. [4] believed that the maximum shear stress was about two times higher near the rim under the nonuniform contact stress compared with the uniform stress. Therefore, the scientific evaluation of the shear strength and shear modulus of asphalt mixture was important for guiding the design of asphalt mixture and reducing the shear failure of asphalt pavement.

The triaxial test method was derived from a geotechnical test used for performance studies of asphalt mixtures in the 1940 s and is still in use today. With the assumption that the asphalt mixture was an isotropic homogeneous material, the basic principle was to place the specimen under a threedirection force by applying a confined pressure and an axial load. The method was also further developed to test the application process, such as the application of confined pressure from the earliest hydraulic pressure to air pressure and from a static triaxial test to a dynamic triaxial test [5]. The method was essentially a confined compression test [6], with the axial principal stress the main factor of the specimen failure. The cohesion, internal friction angle, and shear strength of the asphalt mixture were calculated according to the Mohr-Coulomb theory. Brown [7] pointed out that the 
triaxial test method could only simulate the application of one direction of tensile stress, while there were lateral and longitudinal tensile stresses on the pavement surface in fact.

The standard test method to determine the shear strength of an asphalt mixture by the triaxial test had not yet been developed. However, the Chinese Standard Test Methods of Asphalt and Asphalt Mixture for Highway Engineering (JTG E20-2011) recommended the test to determine the shear strength of asphalt mixtures as a standard test. This method also has certain defects. Firstly, because the lateral pressure of the asphalt mixture on the pavement surface layer could not be accurately measured, the confined pressure used in the test could not accurately reflect the actual stress state of the pavement structure. Secondly, this test method was derived from a soil mechanics test, and the material properties of the asphalt mixture are different from the material parameters and test conditions assumptions in soil mechanics. In addition, the test equipment is expensive and the operation is tedious, which also affects the promotion of the test method.

On the basis of relevant research, Xie and Wang proposed a torsional shear test method under normal stress conditions [8]. The principle was to convert the vertical force into torque through the rack and gear, so that the circular cross section specimen could be sheared. Through theoretical analysis and laboratory experiments, the failure mode of the design test was shear failure, which could be used to evaluate the shear performance of an asphalt mixture. That is a more economical and simple method to obtain the shear strength and parameters of the asphalt mixture.

In the paper, a torsional shear test and triaxial test were conducted with different mixtures and asphalts under different temperatures. The results of cohesion $C$ and internal friction angle $\varphi$ of asphalt mixtures were analyzed, and the differences and the correlation between two methods were obtained to verify the reliability and effectiveness of the torsional shear test method.

\section{Torsional Shear Test under Normal Stress Conditions}

The principle of the torsional shear test method under normal stress conditions is to apply a normal stress $\sigma$ to the test specimen through the jack, then convert the vertical load into a torque $\mathrm{Me}$ through the rack and the gear, placing the cylindrical specimen of asphalt mixture under the compressshear state, thereby causing the specimen to be destroyed. The shear strength, cohesion $C$, and internal friction angle $\varphi$ of the asphalt mixture could be obtained through analysis. The shear fatigue test could also be carried out to obtain the fatigue life of the asphalt mixture specimen. The principle of the test method is shown in Figure 1, and the test device is shown in Figure 2.

The advantages of this method are as follows: The cylindrical specimen was subjected to torque and normal stress at the same time, and the torque and normal stress could be combined to simulate the actual stress state of the pavement structure. In addition, the test method was easy to operate, and the reproducibility of test results also was good.

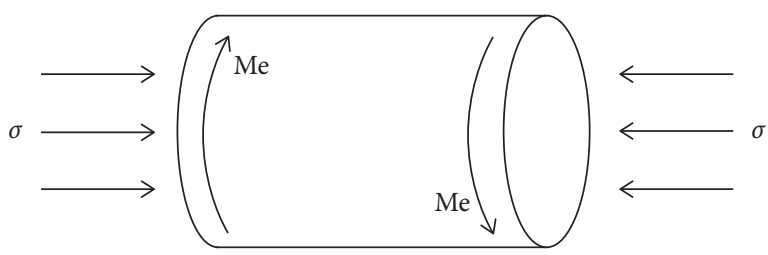

FIGURE 1: Schematic diagram of test method.

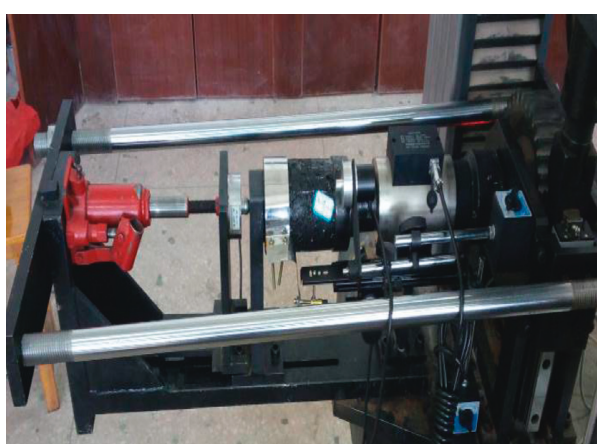

Figure 2: Torsion test device.

The formula for calculating the maximum shear stress is

$$
\tau_{\max }=\frac{T \times r}{I_{p}}=\frac{2 T}{\pi \times r^{3}},
$$

where $T$ is the torque, $I_{p}$ is the sectional inertial torque, $r$ is the radius of the specimen, and $\tau_{\max }$ is the maximum shear strength.

Torsional shear tests were carried out under different normal stresses, as shown in Figure 3, and the MohrCoulomb failure envelope curve was defined as

$$
\tau=C+\sigma \cdot \tan \varphi,
$$

where $\tau$ is the shear stress, $\sigma$ is the normal stress, $C$ is the cohesion, $\varphi$ is the internal friction angle, and $\tan \varphi$ is the slope of the failure envelope curve.

The principal stresses can be calculated according to the following formula:

$$
\left\{\begin{array}{l}
\sigma_{1}=\frac{\sigma_{x}}{2}+\frac{1}{2} \sqrt{\sigma_{x}^{2}+4 \tau_{x}^{2}}, \\
\sigma_{3}=-\left(\frac{1}{2} \sqrt{\sigma_{x}^{2}+4 \tau_{x}^{2}}-\frac{\sigma_{x}}{2}\right)=\frac{\sigma_{x}}{2}-\frac{1}{2} \sqrt{\sigma_{x}^{2}+4 \tau_{x}^{2}}, \\
\sigma_{2}=0 .
\end{array}\right.
$$

$p$ and $q$ were used for determining the coordinates of the maximum shear stress Mohr circle; then, the $k_{f}$ line was obtained by linear regression:

$$
\begin{aligned}
& p=\frac{\left(\sigma_{1}+\sigma_{3}\right)}{2}, \\
& q=\frac{\left(\sigma_{1}-\sigma_{3}\right)}{2} .
\end{aligned}
$$

According to the $k_{f}$ line, the intercept $a_{0}$ and angle $\alpha$ from the ordinate were determined; then, $C$ and $\varphi$ of the 


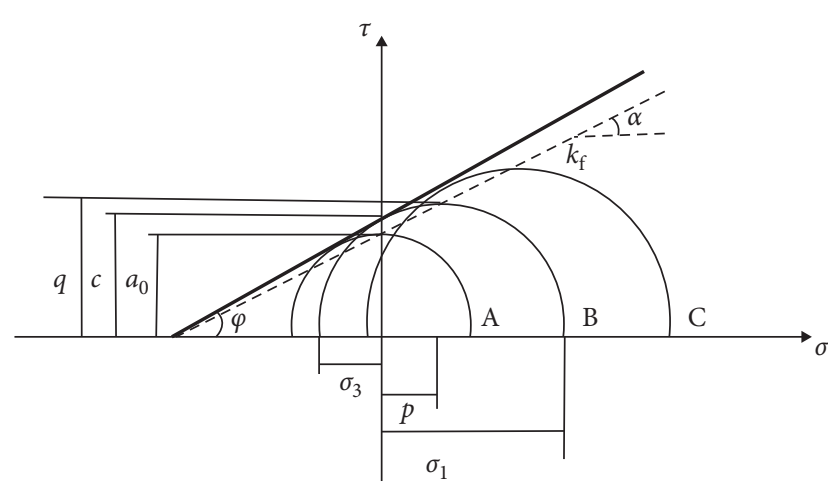

Figure 3: Mohr stress circle under normal stress.

mixture could be obtained according to the following formula:

$$
\begin{aligned}
& \varphi=\sin ^{-1}(\tan \alpha), \\
& c=\frac{a_{0}}{\cos \varphi} .
\end{aligned}
$$

\section{Materials and Specimen Preparation}

Asphalt mixtures of AC-13 and AC-20 were used for the torsional shear test and triaxial test, which are commonly used in China.

The SBS-modified asphalt was selected for the asphalt mixture, and the relevant properties of asphalt including penetration, ductility, softening point, density, etc., were tested according to the Chinese Standard Test Methods of Asphalt and Asphalt Mixture for Highway Engineering (JTG E20-2011), and they meet the requirements of specification.

Limestone was selected for the aggregate, and the filler was obtained by using milled limestone powder. The Los Angeles wear loss, polishing value, density, flat and elongated particles content, adhesion, angularity, sand equivalent, etc., were tested in accordance with the requirements of the Chinese Test Method of Aggregate for Highway Engineering (JTG E42-2005), and they met the requirements of specification.

The gradation of asphalt mixtures is shown in Figures 4 and 5 .

The Marshall method was used for the mixture design, and the Optimal Asphalt Aggregate Ratio and related volume parameters were obtained as shown in Table 1.

The specimen was molded by the Superpave gyratory compactor molding method (SGC), which simulated the asphalt mixture pavement construction process through rotary compaction patterns and made the specimen compact more densely. The paper selected cylindrical specimens with a size of $\Phi 100 \mathrm{~mm} \times 100 \mathrm{~mm}$ for testing. After the sample was completely cooled, the appearance of the sample was checked to meet the requirements, and the height of the specimen was measured at five different positions with a Vernier caliper, where the difference between the highest and lowest positions should be no more than $2 \mathrm{~mm}$. The specimens are shown in Figure 6.

In the paper, three specimens were parallel-tested.

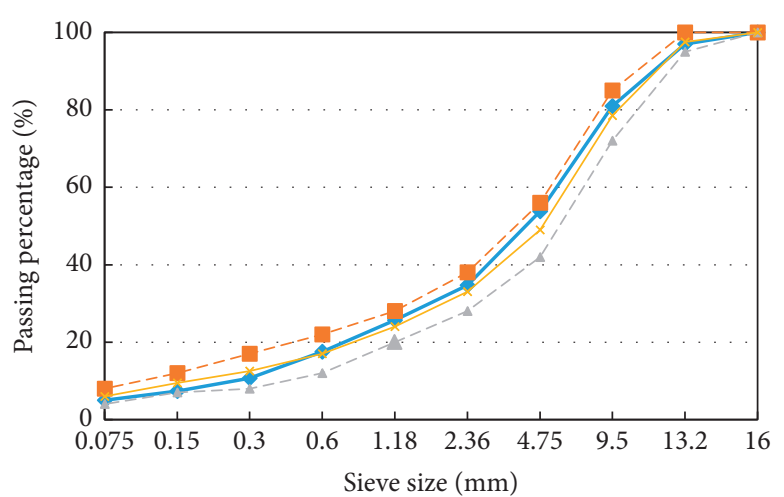

$$
\begin{aligned}
& - \text { Target gradation } \quad-\star-\text { Lower gradation } \\
& -\square-\text { Upper gradation } \quad \rightarrow-\text { Mid gradation }
\end{aligned}
$$

Figure 4: Gradation curve of asphalt mixtures of AC-13.

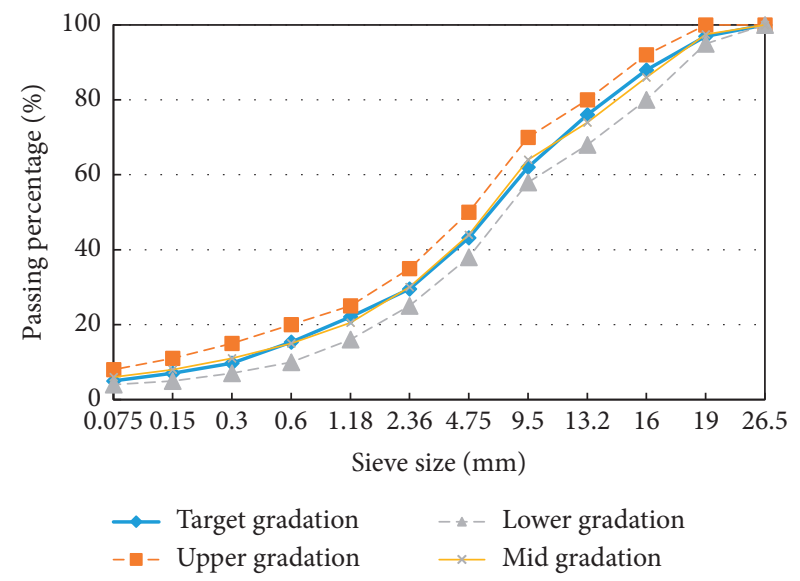

FIGURE 5: Gradation curve of asphalt mixtures of AC-20.

\section{Test Conditions}

For the torsional shear test, $20^{\circ} \mathrm{C}, 40^{\circ} \mathrm{C}$, and $60^{\circ} \mathrm{C}$ were selected as the test temperatures for the comparative study, and the loading rate was $1 \mathrm{~mm} / \mathrm{min}$. Three normal stress levels of $0 \mathrm{MPa}, 0.35 \mathrm{MPa}$, and $0.7 \mathrm{MPa}$ (China's standard tire stress) were selected for testing.

The Dynatriax 100/14 dynamic and static triaxial test system of Controls/WF was used in the triaxial test. $20^{\circ} \mathrm{C}$, $40^{\circ} \mathrm{C}$, and $60^{\circ} \mathrm{C}$ were selected as the test temperatures, and the loading rate was $1 \mathrm{~mm} / \mathrm{min}$. The confined pressures of $0 \mathrm{MPa}, 0.138 \mathrm{MPa}$, and $0.276 \mathrm{MPa}$ were selected. The test mode and equipment are shown in Figure 7.

In addition, in order to compare the shear properties of different types of asphalts, the asphalt mixture of AC-13 with unmodified asphalt and SBS-modified asphalt was carried out on the torsional shear test and triaxial test.

\section{Analysis of Results}

5.1. Comparison of Failure Crack Spreading. The specimens after the torsional shear test and the triaxial test are shown in Figures 8 and 9 . 
TABLE 1: Summary of volumetric parameters of asphalt mixture.

\begin{tabular}{|c|c|c|c|c|c|c|c|}
\hline Mixture type & $\begin{array}{c}\text { Optimal asphalt } \\
\text { aggregate ratio (\%) }\end{array}$ & $\begin{array}{c}\text { Bulk density } \\
\left(\mathrm{g} / \mathrm{cm}^{3}\right)\end{array}$ & Stability (kN) & Flow value $(\mathrm{mm})$ & Air voids (\%) & VMA (\%) & VFA (\%) \\
\hline AC-13 & 4.9 & 2.415 & 13.85 & 3.05 & 4.7 & 14.7 & 68.2 \\
\hline AC-20 & 4.5 & 2.450 & 14.02 & 2.83 & 3.9 & 13.3 & 70.5 \\
\hline
\end{tabular}
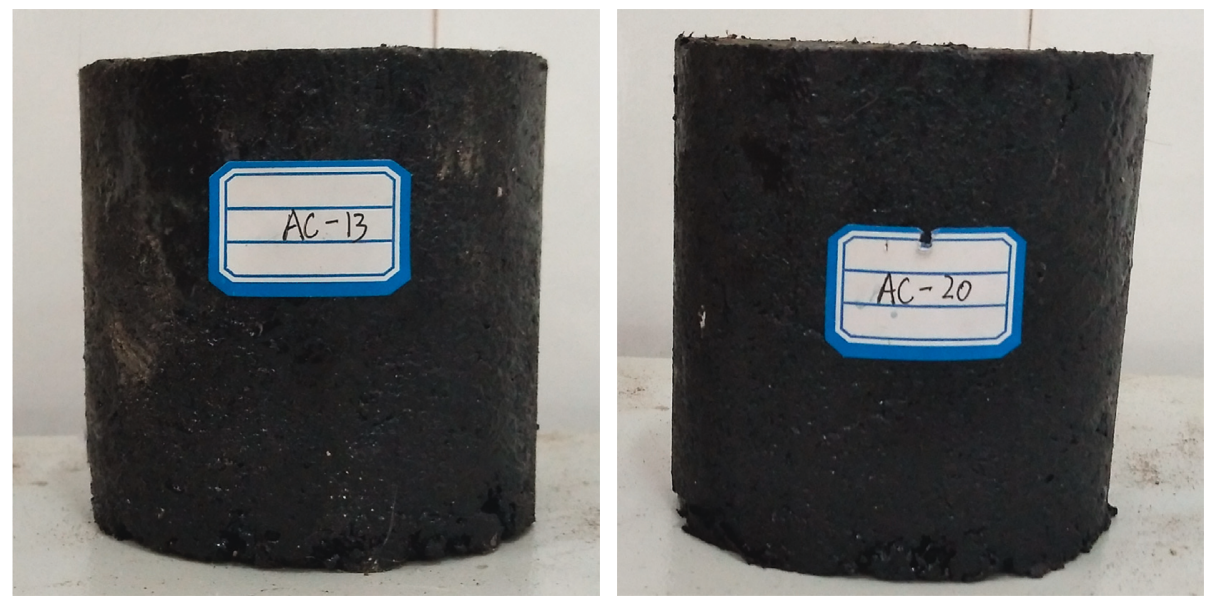

Figure 6: Asphalt mixture specimens ((a) AC-13, (b) AC-20).

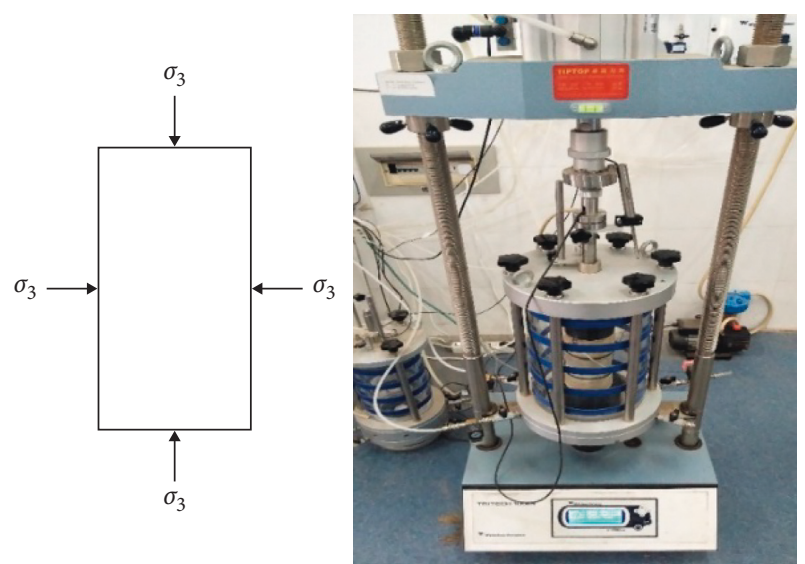

Figure 7: Triaxial test mode and equipment.

As shown in Figure 8, under the action of torque and normal stress, a crack spreading to both ends at an oblique angle of about $45^{\circ}$ from the axis appeared on the surface of the specimen, and a bulge also occurred around the specimen.

As shown in Figure 9, after the test, a crack spread along the vertical direction, and the specimen bulged around the surface uniformly.

The crack spreading routine and the spreading angle were different in two test methods as a result of different loading modes for the specimens. Under the torque action in the torsional test, the maximum stress appeared at a $45^{\circ}$ angle from the axis on the surface of the specimen and resulted in an oblique crack, which also indicated it was a typical shear failure mode. In the triaxial test, the specimen was in a state of compression with confined stress, and the shear stress existed along the vertical direction and resulted in a vertical crack. From the view of the crack spreading patterns, the torsional test may simulate the shear failure of the asphalt mixtures better.

5.2. Comparison of Results of Different Gradation. The asphalt mixture consisted of asphalt and mineral materials, and its shear strength was derived from the bonding of the asphalt binder and the interlock of the aggregates. Studies have shown that about $60 \%$ of the shear properties of asphalt mixtures rely on the interlock of aggregate grades, and $40 \%$ rely on the cohesion of asphalt under high-temperature conditions [9].

The differences of the $C$ and $\varphi$ values were compared between the asphalt mixtures of AC-13 and AC-20. The results of the average and standard deviations are shown in Figures 10 and 11.

As shown in Figure 10, the cohesion $C$ of the torsional test was slightly larger than that of the triaxial test, and both had small deviations. The specimen was subjected to the full surrounding confined pressure state in the triaxial test and was only subjected to normal stress and torque in the torsional shear test, which may be the main cause of the difference in cohesion.

Further, with the nominal maximum aggregate size increasing, the cohesion $C$ of the mixture decreased. The reason for this is that when the nominal maximum aggregate size was small, the content of the fine aggregate in the mixture was relatively large, which made the specific surface area of the aggregate increase, resulting in an increase in the amount of asphalt, an increase in the proportion of structural asphalt, and an increase in the contact between the aggregate and the asphalt. Therefore, the cohesion was larger. 

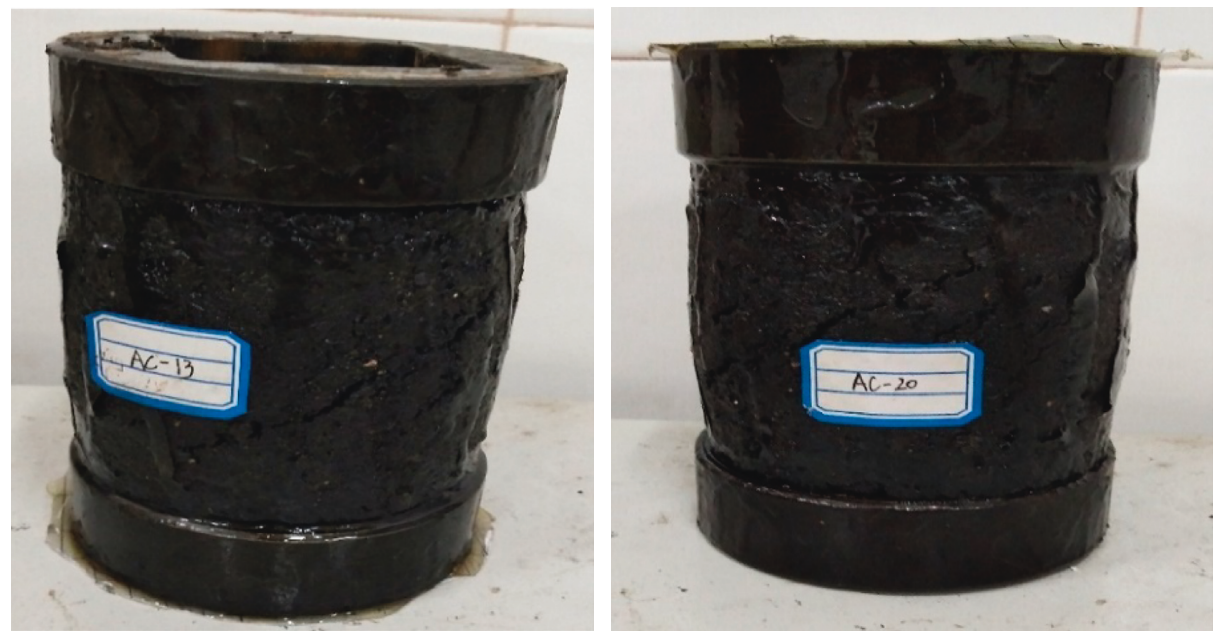

Figure 8: Failure specimens of torsional shear test ((a) AC-13; (b) AC-20).
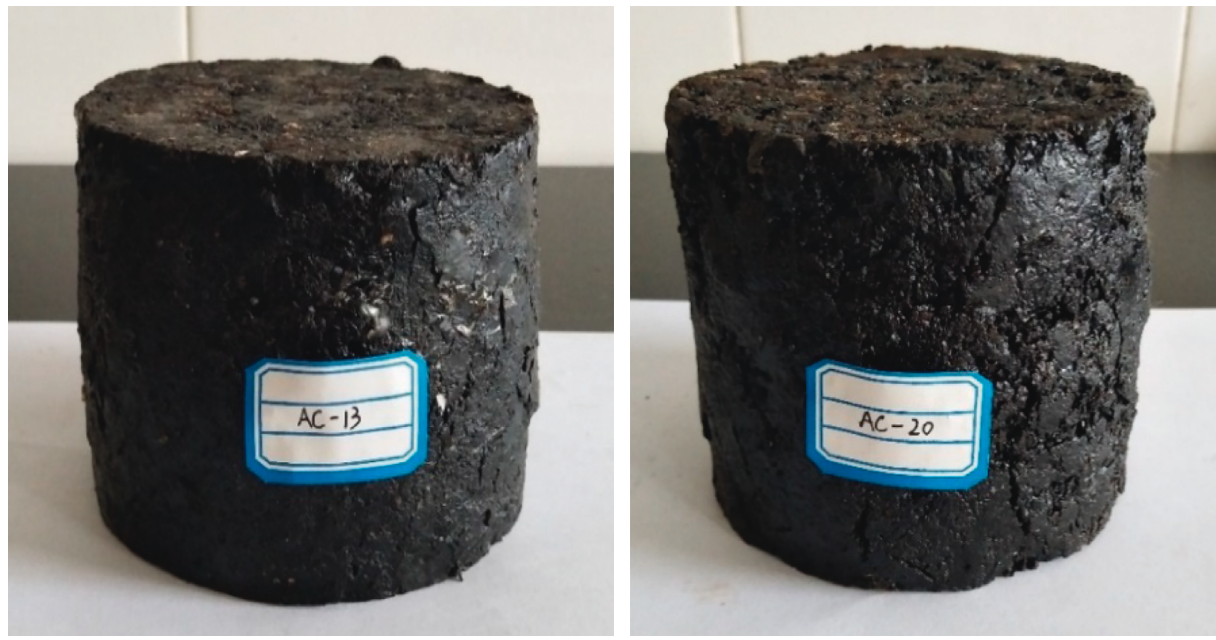

FIgURE 9: Failure specimens of triaxial test ((a) AC-13; (b) AC-20).

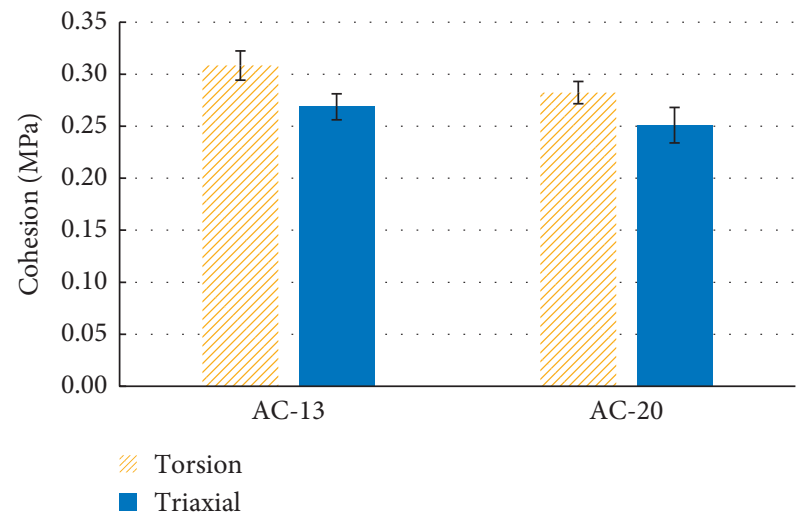

Figure 10: Results of cohesion $C$ of different mixtures $\left(60^{\circ} \mathrm{C}\right)$.

As shown in Figure 11, the internal friction angle $\varphi$ was basically equivalent in the two methods for the same asphalt mixtures, which was consistent with the results obtained in the literature [10], although showing a slightly high deviation. This indicated that the internal friction angle was

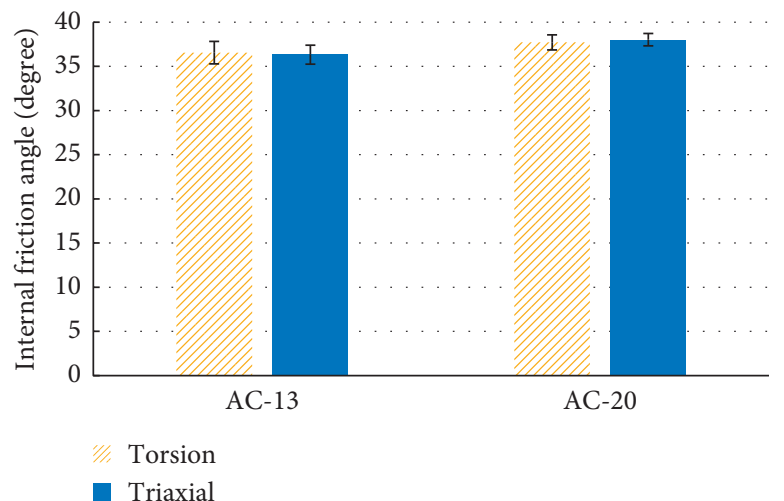

FIGURE 11: Results of internal friction angle $\varphi$ of different mixtures $\left(60^{\circ} \mathrm{C}\right)$.

mainly related to the asphalt mixture gradation under the same molding way, which was the mutual interlock of aggregates, and the external conditions such as the test method had little effect on it. 
In addition, with the nominal maximum aggregate size increase, the internal friction angle $\varphi$ of the mixture increased. That is, as the nominal maximum aggregate size was larger, the content of coarse aggregate in the gradation of the mixture increased, and the possibility that the coarse aggregates contacted each other to interlock increased, resulting in an increase in the internal friction angle.

\subsection{Comparison of Results of Different Types of Asphalt.} The shear test for the asphalt mixture of AC-13 with an unmodified asphalt and SBS modified asphalt were carried on, and the results of the average and standard deviations are shown in Figures 12 and 13.

As shown in Figure 12, the cohesion $C$ of the torsional test was slightly larger than that of the triaxial test, and both have a small deviation, which is also consistent with the conclusion of Section 5.2.

In addition, the cohesion $C$ of the modified asphalt mixture was larger than that of the unmodified asphalt. The asphalt mixture was a multistage space network structure composed of dispersed mineral aggregates and asphalt, its shear strength was greatly affected by the concentration of the dispersed phase and the viscosity of the dispersion medium. The asphalt with high viscosity could provide larger viscous resistance, and the high viscosity of the modified asphalt was the reason that it had a larger cohesion than that of the unmodified asphalt mixture.

As shown in Figure 13, the internal friction angle $\varphi$ was basically equivalent in the two methods for the two types of asphalt, the unmodified and modified asphalts, although it showed a slightly high deviation. This indicates that the internal friction angle was mainly related to the asphalt mixture gradation, and the internal friction angle of the mixture was determined by the mutual interlock of aggregates, which is consistent with the conclusion of Section 5.2.

\subsection{Comparison of Results under Different Temperature.}

The asphalt mixture of AC-13 was selected for the torsional shear test and triaxial test at $20^{\circ} \mathrm{C}, 40^{\circ} \mathrm{C}$, and $60^{\circ} \mathrm{C}$. The specimens were kept in the environmental chamber for 6 hours before the test. The results of the average and standard deviations are shown in Figures 14-17.

As shown in Figure 14, the cohesion $C$ of the torsional test was slightly larger than that of the triaxial test under the three temperatures, which is also consistent with the conclusions of Sections 5.2 and 5.3.

As shown in Figure 15 , from $20^{\circ} \mathrm{C}$ to $40^{\circ} \mathrm{C}$, the value of cohesion $C$ in the torsional shear test and the triaxial test decreased by $11.8 \%$ and $14.5 \%$, respectively, and the value of cohesion $C$ decreased by $31.7 \%$ and $35.3 \%$ from $40^{\circ} \mathrm{C}$ to $60^{\circ} \mathrm{C}$, respectively. This indicates that the temperature change had a greater influence on the cohesion $C$, and the higher the temperature, the greater the cohesion $C$ decrease.

As shown in Figure 16, the internal friction angle $\varphi$ was basically equivalent in two methods under three

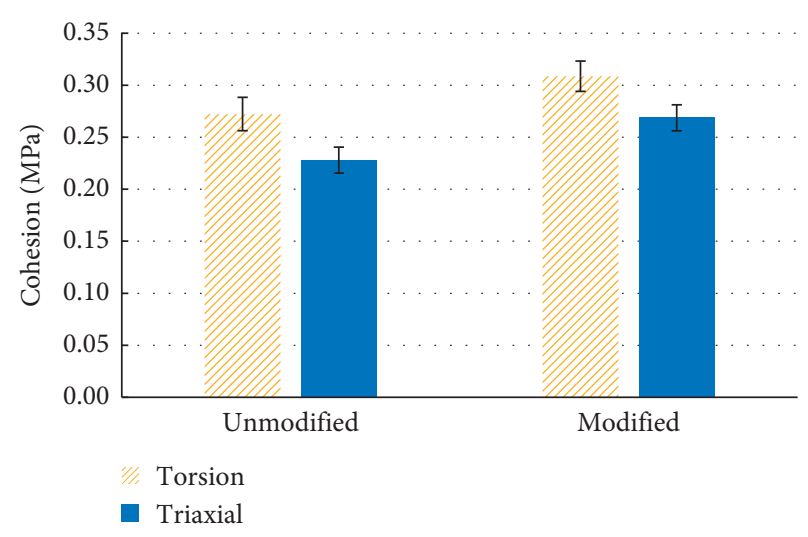

FIgURE 12: Results of cohesion $C$ of different types of asphalt $\left(60^{\circ} \mathrm{C}\right)$.

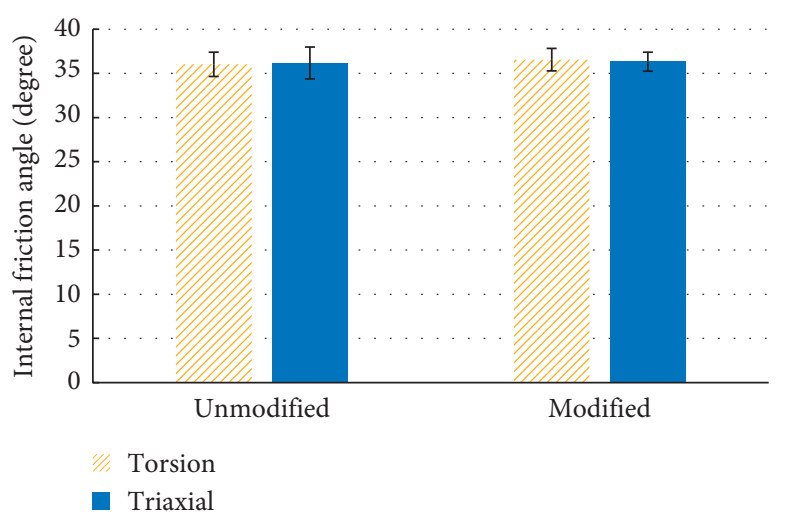

FIgURE 13: Results of internal friction angle $\varphi$ of different types of asphalt $\left(60^{\circ} \mathrm{C}\right)$.

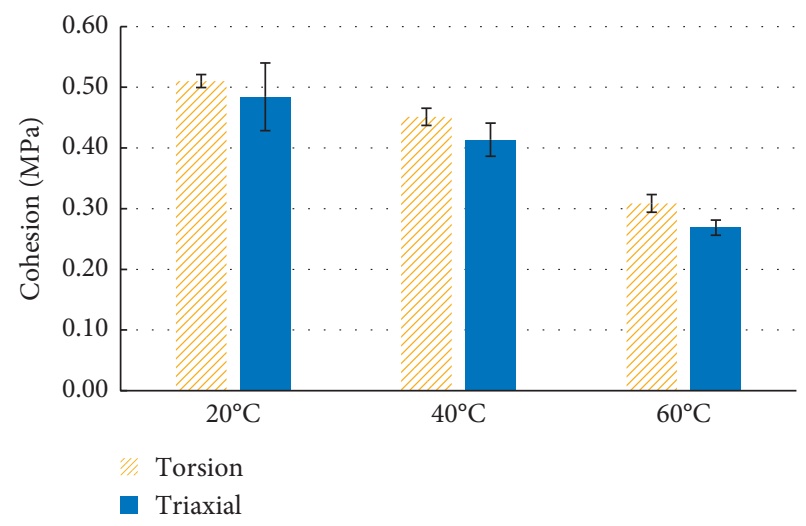

Figure 14: Results of cohesion $C$ at different temperatures.

temperatures, although showing slightly high deviation, which is also consistent with the conclusions of Sections 5.2 and 5.3 .

In addition, as shown in Figure 17 , from $20^{\circ} \mathrm{C}$ to $40^{\circ} \mathrm{C}$, the internal friction angle $\varphi$ of the torsional shear test and the triaxial test decreased by $1.5 \%$ and $1.3 \%$, respectively, from $40^{\circ} \mathrm{C}$ to $60^{\circ} \mathrm{C}$, the internal friction angle $\varphi$ decreased by $2.2 \%$ and $3.4 \%$, and the range scope of decrease was not large. This indicates that the temperature change had little effect on the 


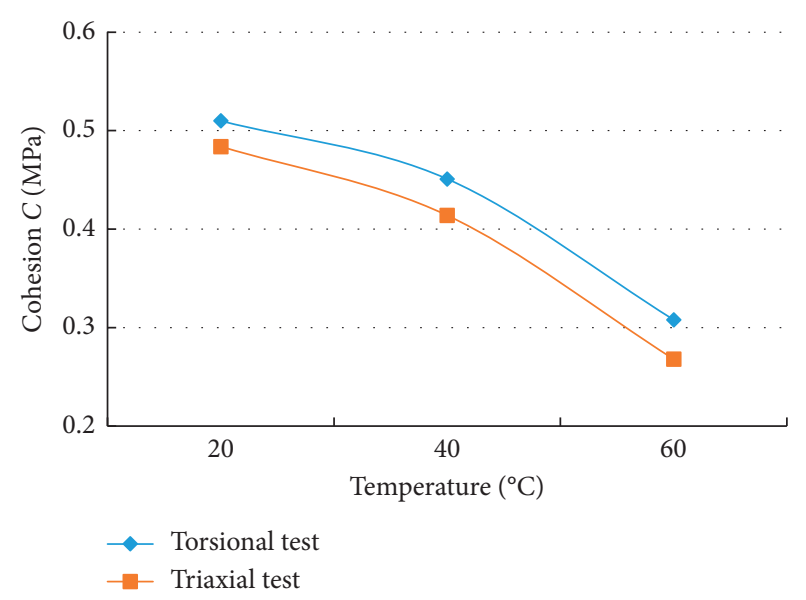

Figure 15: Distribution of the cohesion $C$ at different temperatures.

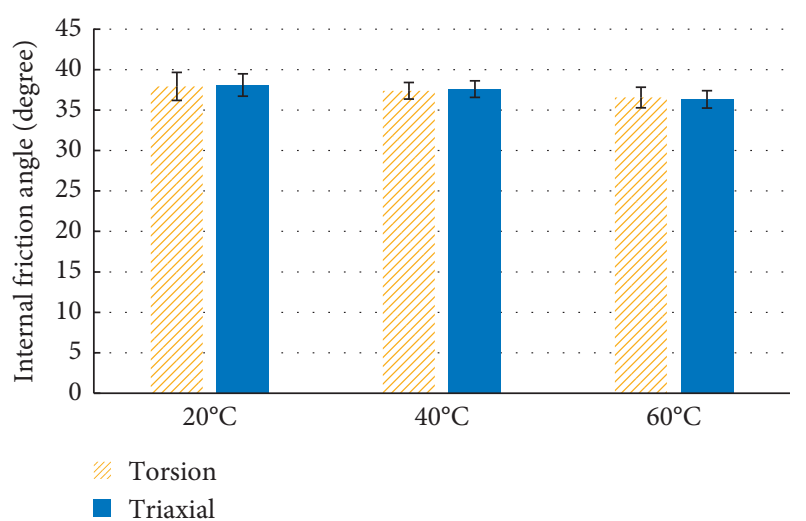

FIgURE 16: Results of internal friction angle $\varphi$ at different temperatures.

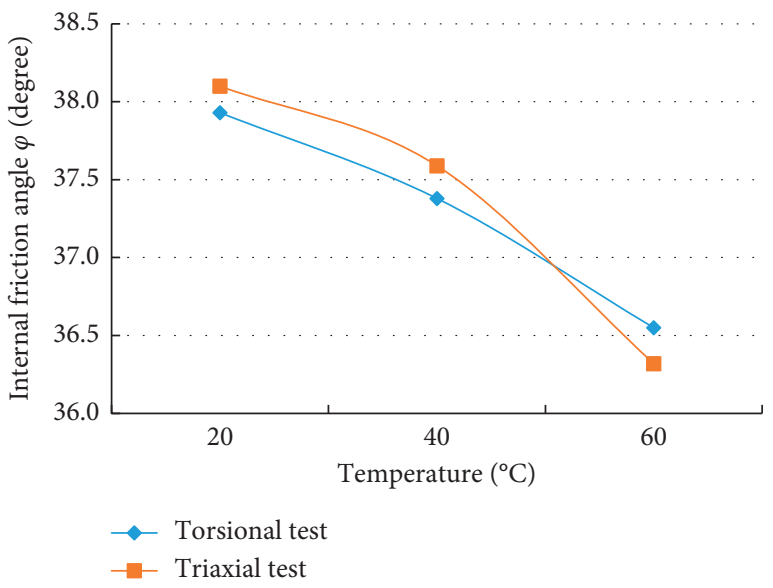

FIGURE 17: Distribution of the internal friction angle $\varphi$ at different temperatures.

value of the internal friction angle $\varphi$. This was also consistent with the above conclusions. The internal friction angle was mainly determined by the aggregate gradation of the mixture itself, and external conditions such as temperature had little effect on it.
5.5. Correlation Analysis of Two Test Methods. The analysis of variance (ANOVA) method [11] was applied to investigate the significance of the torsional shear test and triaxial test and is a versatile statistical tool for studying the relation between a dependent variable and one or more independent variables. Each independent variable is assigned a $P$ value within the ANOVA. The significance level employed in this investigation was 0.05 . The $P$ values are shown in Table 2 .

In Table 2, "No" indicates there is no statistical difference and "Yes" indicates there is a statistical difference. So, except for where several $P$ values of cohesion $C$ are less than $0.05, P$ values are more than 0.05 , which indicates that there is no statistical difference for the results of two methods.

To provide a better understanding, the least squares regression analysis was performed on $C$ and $\varphi$ was obtained under different temperature conditions. The results are shown in Figure 18.

As shown in Figure 18, the R-square equals 0.67 and 0.91 for cohesion $C$ and the internal friction angle $\varphi$, respectively. The result of the torsional shear test has a good correlation with the results of the triaxial test.

The difference in the value of cohesion $C$ between the two test modes was about 15-20\%, indicating that the different test methods and test conditions had a certain influence on the cohesion results.

\section{Conclusions}

The asphalt mixtures of AC-13 and AC-20 with two different asphalt types (unmodified asphalt and SBS modified asphalt) were selected to conduct the comparative study under three temperature conditions of $20^{\circ} \mathrm{C}, 40^{\circ} \mathrm{C}$, and $60^{\circ} \mathrm{C}$ using torsional shear tests under normal stress and the triaxial test.

(i) The crack spreading routine and the spreading angle were different in the two test methods, which reflects the effects of different loading modes for the specimens. From the view of the crack spreading patterns, the torsional test may simulate the shear failure of the asphalt mixtures better.

(ii) The cohesion $C$ of the torsional test was slightly larger than that of the triaxial test for different mixtures, asphalts, and temperatures. The specimen was subjected to the full surrounding confined pressure state in the triaxial test, and only subjected to normal stress and torque in the torsional shear test, which may be the main cause of the difference in cohesion.

(iii) The internal friction angle $\varphi$ was basically equivalent in two methods for different mixtures, asphalts, and temperatures. This indicates that the internal friction angle was mainly related to the spatial distribution of the aggregates or the mutual interlock, and the external conditions such as the test method, asphalt types, and temperatures had little effect on it.

(iv) The results of the ANOVA and regression analysis indicated that there is no statistical difference for the 
TABle 2: Summary of $P$ values of two methods.

\begin{tabular}{lcccc}
\hline Comparison item & $P$ values $(C)$ & Significant $(C)$ & $P$ values $(\varphi)$ & Significant $(\varphi)$ \\
\hline Gradation AC-13 & 0.022 & Yes & 0.823 & No \\
Gradation AC-20 & 0.065 & No & 0.653 & No \\
Asphalt-unmodified & 0.022 & Yes & 0.911 & No \\
Asphalt-modified & 0.023 & Yes & 0.823 & No \\
Temperature $20^{\circ} \mathrm{C}$ & 0.506 & No & 0.899 & No \\
Temperature $40^{\circ} \mathrm{C}$ & 0.124 & No & 0.817 & No \\
Temperature $60^{\circ} \mathrm{C}$ & 0.024 & Yes & 0.822 & No \\
\hline
\end{tabular}

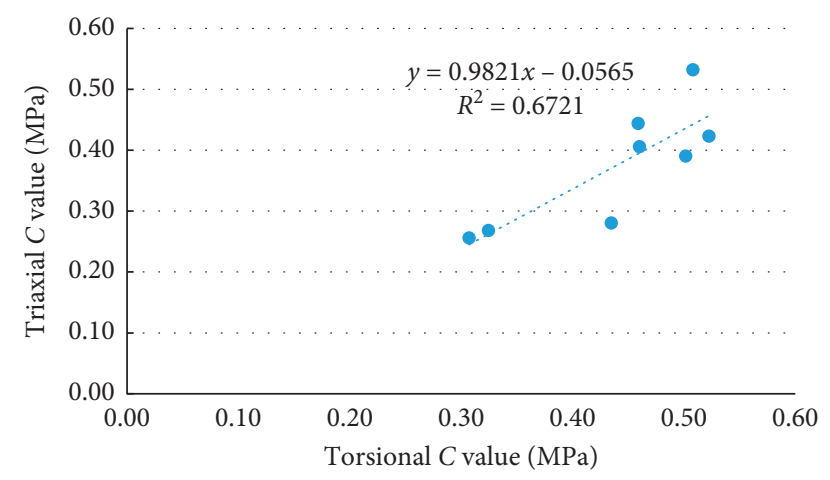

Ministry of Education (grant no. Kfj080107) in Changsha University of Science \& Technology.

\section{References}

[1] M. Novak, B. Birgisson, and R. Roque, "Near-surface stress states in flexible pavements using measured radial tire contact stresses and ADINA," Computers and Structures, vol. 81, no. 8-11, pp. 859-870, 2003.

[2] F. Gu, W. Ma, R. C. West, A. J. Taylor, and Y. Zhang, "Structural performance and sustainability assessment of cold central-plant and in-place recycled asphalt pavements: a case study," Journal of Cleaner Production, vol. 208, pp. 1513-1523, 2019.

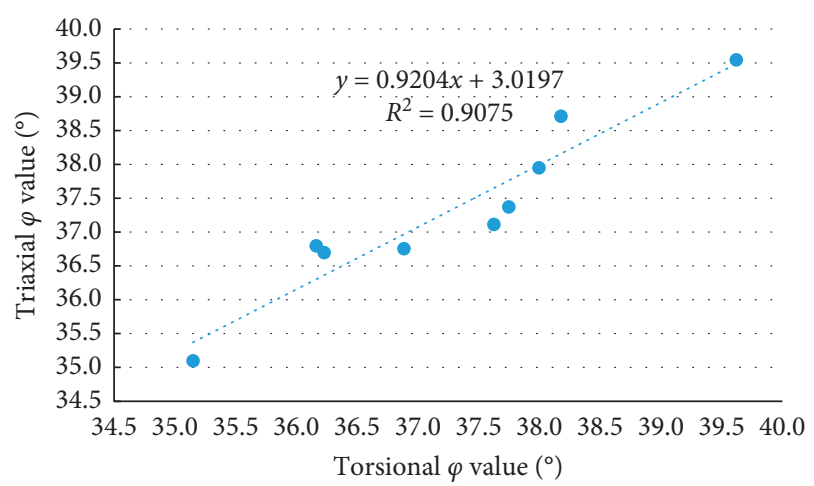

[3] L. Myers, R. Roque, and B. Ruth, "Mechanisms of surfaceinitiated longitudinal wheel path cracks in high-type bituminous pavements," Journal of Association of Asphalt Paving Technologists, vol. 67, pp. 401-419, 1998.

[4] G. Wang, R. Roque, and D. Morian, "Evaluation of nearsurface stress states in asphalt concrete pavement: threedimensional tire-pavement contact model," Transportation Research Record: Journal of the Transportation Research Board, vol. 2227, no. 1, pp. 119-128, 2011.

[5] A. Ulloa, E. Y. Hajj, and P. E. Sebaaly, "Mechanistic-based approach to evaluate rutting susceptibility of hot-mix asphalt mixtures by use of dynamic triaxial testing," Transportation Research Record, vol. 2373, no. 1, pp. 121-133, 2013.

FIgURE 18: Regression of the results of the two test methods.

results of two test methods; they have a good correlation, which demonstrates that the torsional shear test is a reliable and effective laboratory test method for evaluating the shear performance of asphalt mixtures.

\section{Data Availability}

The data used to support the findings of this study are included within the article.

\section{Conflicts of Interest}

The authors declare no conflict of interest.

\section{Acknowledgments}

The authors would like to acknowledge the financial support of the National Natural Science Foundation of China (grant no. 51008039) and the China Scholarship Council (grant no. 201808430101) and also the Open Fund support of Key Laboratory of Highway Engineering of

6] W. H. Goetz and J. H. Schaub, "Triaxial testing of bituminous mixtures," in Bituminous Paving Materials, pp. 51-63, ASTM International, West Conshohocken, PA, USA, 1959.

[7] S. F. Brown, "Improved framework for predicting permanent deformation in asphalt layers," Transportation Research Record, vol. 537, pp. 18-30, 1975.

[8] J. Xie and J.-W Wang, "Study on torsional shear test method for asphalt mixture under normal stress condition," Journal of Highway and Transportation Research and Development, vol. 34, no. 7, pp. 1-7, 2017, in Chinese.

[9] M. Guler, H. U. Bahia, P. J. Bosscher et al., "Device for measuring shear resistance of hot-mix asphalt in gyratory compactor," Transportation Research Record, vol. 1723, no. 1, pp. 116-124, 2000.

[10] S.-A. Tan, B.-H. Low, and T. F. Fwa, "Behavior of asphalt concrete mixtures in triaxial compression," Journal of Testing and Evaluation, vol. 22, no. 3, pp. 195-203, 1994.

[11] R. L. Ott and M. T. Longnecker, An Introduction to Statistical Methods and Data Analysis, Nelson Education, Scarborough, Canada, 2015. 


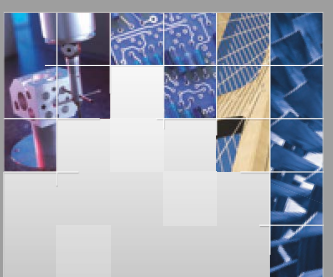

\section{Enfincering}
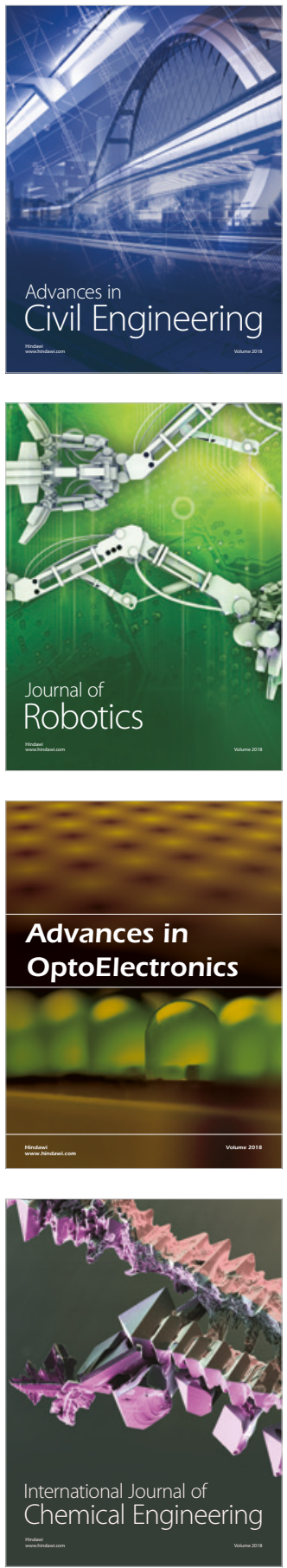

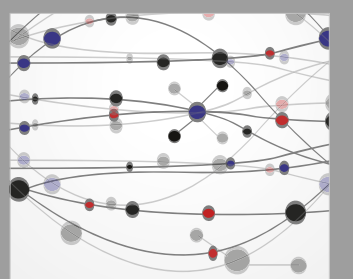

\section{Rotating \\ Machinery}

The Scientific World Journal

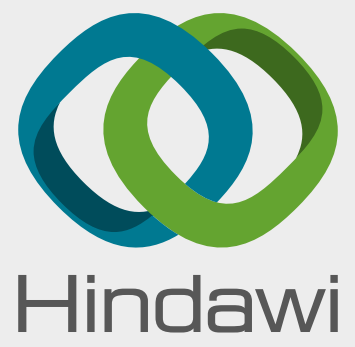

Submit your manuscripts at

www.hindawi.com
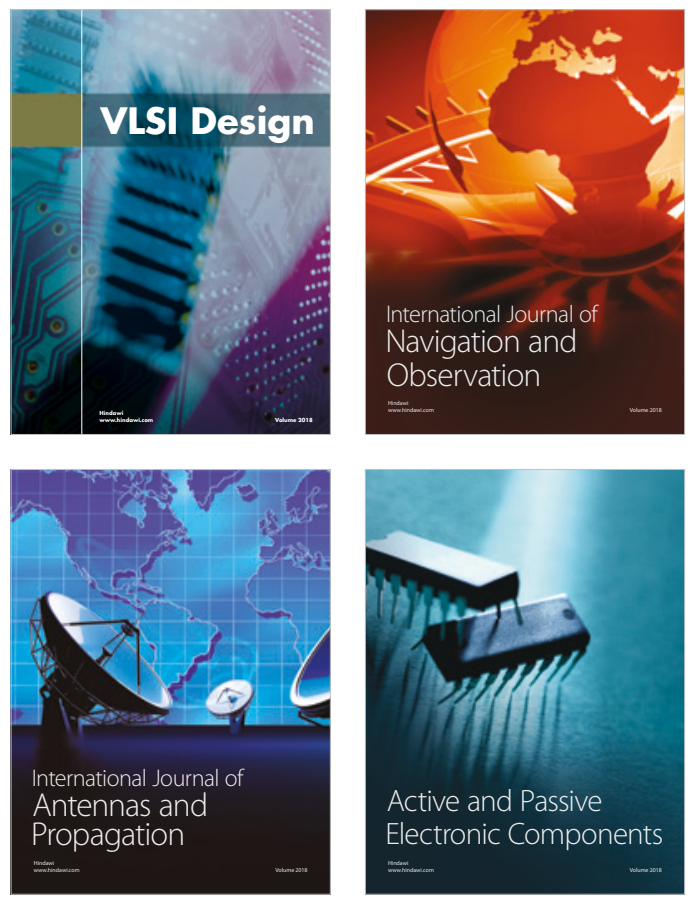
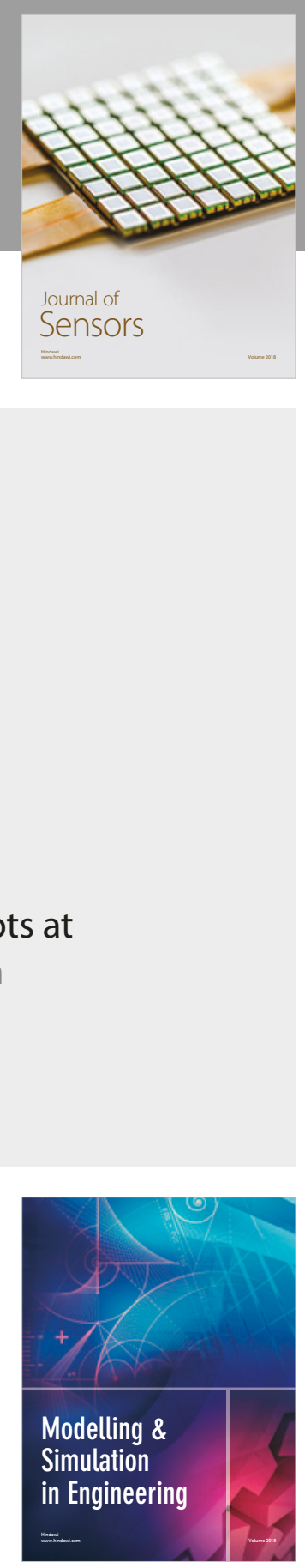

\section{Advances \\ Multimedia}
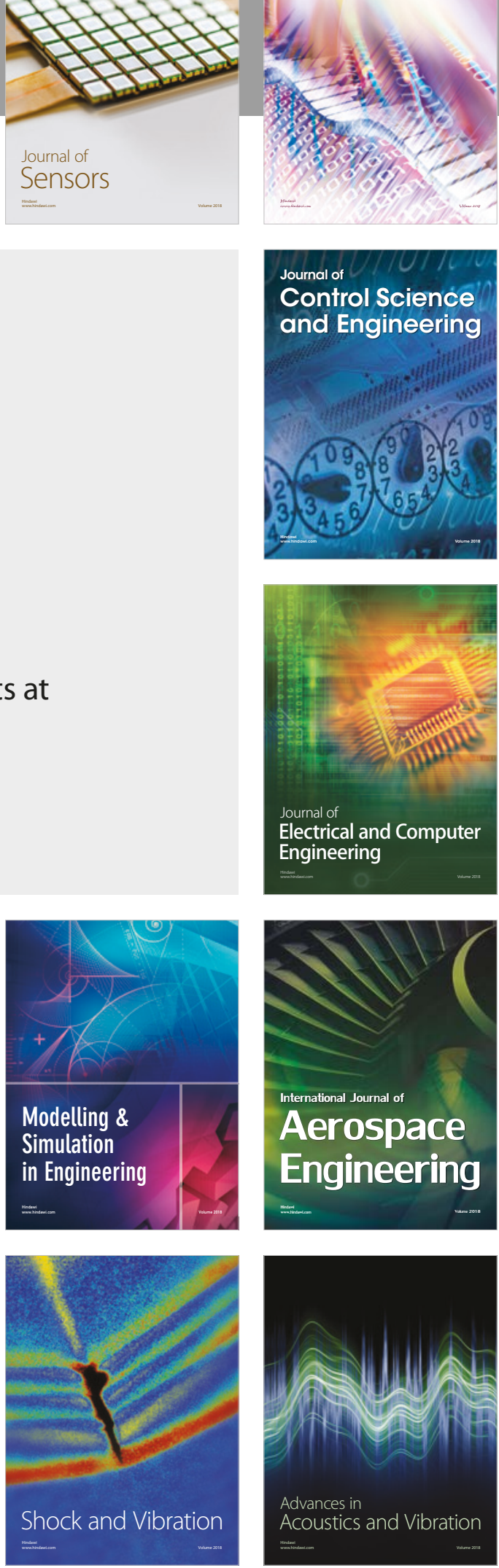